\title{
ANALISIS DESTINASI PARIWISATA PULAU KELAPA DAN PULAU HARAPAN DI KEPULAUAN SERIBU JAKARTA
}

\author{
Miswan Miswan', Uuh Sukaesih ${ }^{2}$ \\ Fakultas Ekonomi dan Bisnis, Universitas Sahid \\ Jl. Soepomo No 84, Jakarta Selatan \\ Email Korespondensi:miswankisaran@yahoo.com
}

\begin{abstract}
ABSTRAK
Penelitian ini bertujuan untuk mengkaji kualitas destinasi pariwisata meliputi daya tarik, fasilitas, dan aksesibilitas pariwisata di Pulau Kelapa dan Pulau Harapan di Kepulauan Seribu Jakarta. Penelitian dilakukan dengan menyebarkan kuesioner kepada100 orang yang sudah mengunjungi objek wisata Pulau Kelapa dan Pulau Harapan. Metode analisis dilakukan dengan analisis deskriptif, yaitu dengan mendeskriptifkan hasil penelitian yang selanjutnya dihitung nilai rataratanya. Hasil penelitian mengenai penilaian wisatawan terhadap kualitas destinasi pariwisata Pulau Kelapa dan Pulau Harapan di Kepulauan Seribu Jakarta dengan skala penilaian 1 sampai 4, diperoleh rata-rata $=3.24$ (kategori baik). Indikator kualitas destinasi wisata yang lebih tinggi dari rata-rata yaitu: 1) Keindahan alam pantai, 2) Keindahan terumbu karang, 3) Ketersediaan penginapan, 4) Ketersediaan penjual makanan dan minuman, 5) Keterjangkauan harga makanan dan minuman, 6) Kenyamanan transportasi, 7) Keterjangkauan biaya transportasi. Indikator kualitas destinasi wisata yang lebih rendah dari rata-rata yaitu: 1) Kebersihan pantai, 2) Ketersediaan fasilitas permainan air, 3) Keterjangkauan harga fasilitas permainan air, 4) Ketersediaan air bersih, 5) Kemudahan transportasi, 6) Keamanan transportasi.
\end{abstract}

Kata Kunci: Destinasi, Pariwisata.

\begin{abstract}
This study aims to examine the quality of tourism destinations including the attraction, facilities, and accessibility of tourism on Coconut Island and Harapan Island in the Thousand Islands Jakarta. The research was conducted by distributing questionnaires to 100 people who had visited the tourist attractions of Kelapa Island and Harapan Island. The method of analysis is carried out by descriptive analysis, namely by describing the results of the study then calculates the average value. The results of the study on rating of tourists on the quality of tourism destinations in Kelapa Island and Harapan Island in the Thousand Islands Jakarta with a rating scale of 1 to 4 , obtained an average $=3.24$ (good category). The quality indicators of tourist destinations are higher than average, namely: 1) The natural beauty of the beach, 2) The beauty of coral reefs, 3) Availability of accommodation, 4) Availability of food and beverage sellers, 5) Affordability of food and beverage prices, 6) Transportation convenience , 7) Affordability of transportation costs. Quality indicators of tourist destinations that are lower than average are: 1) Beach cleanliness, 2) Availability of water play facilities, 3) Affordability of prices for water play facilities, 4) Availability of clean water, 5) Ease of transportation, 6) Transportation security.
\end{abstract}

Keywords: Destinations, Tourism.

\section{PENDAHULUAN}


Industri pariwisata menjadi sektor terpenting dalam suatu negara karena industri pariwisata menjadi salah satu sumber penghasil devisa, serta dapat meningkatkan pertumbuhan ekonomi, dapat meningkatkan kesejahteraan rakyat, membuka lapangan kerja, dan mengatasi pengangguran. Kepulauan Seribu merupakan wilayah Administratif DKI Jakarta yang terdiri dari pulau-pulau, yaitu sekitar sebanyak 110 pulau. Pulau pulau tersebut terbagi dalam pulau yang berpenduduk dan dikunjungi oleh wisatawan dan pulau yang tidak berpenduduk namun dikunjungi wisatawan. Pulau berpenduduk yang dikunjungi wisatawan meliputi pulau Pramuka, Pulau Tidung, Pulau Untung Jawa, Pulau Harapan, Pulau Kelapa, Pulau Pari/Lancang). Pulau yang dimanfaatkan untuk resort yaitu Pulau Ayer, Pulau Bidadari, Pulau Kotok Tengah, Pulau Sepa, Pulau Putri, Pulau Macan, Pulau Pantara. Pulau yang digunakan untuk cagar alam yang dimanfaatkan untuk konservasi yaitu Pulau Onrust, Pulau Rambut dan Pulau Kelor.

Berdasarkan data dari Dinas Pariwisata dan Kebudayaan Kepulauan Seribu jumlah wisatawan di pulau yang berpenduduk lebih banyak dibandingkan pulau-pulau yang tidak berpenduduk, yaitu tahun 2015 sebanyak 96,06 \% dan tahun 2016 sebanyak $84,8 \%$. Banyaknya wisatawan ke pulau yang berpenduduk dikarenakan pulau tersebut sudah lebih baik baik dari segi fasilitas, sarana dan prasarana, serta mudahnya transportasi menuju pulau tersebut. Selain itu harga penginapan di pulau yang berpenduduk lebih murah dibandingkan dengan pulau yang tidak berpenduduk. Pada tahun 2016 jumlah wisatawan ke Pulau yang berpenduduk yaitu: 1). Pulau Untung Jawa $=252669$ orang, 2). Pulau Tidung = 146351 orang, 3). Pulau Pari = 116107 orang, 4) Pulau Pramuka = 88527 orang, 5) Pulau Harapan = 86106 orang, 6) Pulau Kelapa = 35364 orang, dan pulau berpenduduk lainnya $=17392$ orang. Berdasarkan data tersebut jumlah wisatawan paling sedikit yaitu ke Pulau Kelapa dan Pulau Harapan, hal tersebut dikarenakan kedua pulau tersebut berada paling jauh dari daratan Jakarta. Tujuan dari penelitian ini yaitu untuk mengetahui kualitas destinasi pariwisata yang meliputi daya tarik wisata, fasilitas, dan aksesibilitas Pulau Kelapa dan Pulau Harapan di Kepulauan Seribu Jakarta.

\section{Pengertian Pariwisata}

Dalam Undang-Undang RI nomor 10 tahun 2009 tentang Kepariwisataan menjelaskan bahwa, Pariwisata adalah berbagai macam kegiatan wisata dan didukung berbagai fasilitas serta layanan yang disediakan oleh masyarakat, pengusaha, dan pemerintah. Sedangkan wisata merupakan kegiatan perjalanan yang dilakukan oleh seseorang atau sekelompok orang dengan mengunjungi tempat tertentu untuk tujuan rekreasi, pengembangan pribadi, atau mempelajari keunikan daya tarik wisata yang dikunjungi, dalam jangka waktu sementara.

Dalam Undang-undang Nomor 10 Tahun 2009 tentang Kepariwisataan dijelaskan bahwa yang dimaksud dengan:

1. Wisata adalah kegiatan perjalanan yang dilakukan oleh seseorang atau sekelompok orang dengan mengunjungi tempat tertentu untuk tujuan rekreasi, pengembangan pribadi, atau mempelajari keunikan daya Tarik wisata yang dikunjungi dalam jangka waktu sementara.

2. Wisatawan adalah orang yang melakukan wisata.

3. Pariwisata adalah berbagai macam kegiatan wisata dan didukung berbagai fasilitas serta layanan yang disediakan oleh masyarakat, pengusaha, Pemerintah, dan Pemerintah Daerah. 
4. Kepariwisataan adalah keseluruhan kegiatan yang terkait dengan pariwisata dan bersifat multidimensi serta multidisiplin yang muncul sebagai wujud kebutuhan setiap orang dan Negara serta interaksi antara wisatawan dan masyarakat setempat, sesama wisatawan, Pemerintah, Pemerintah Daerah, dan pengusaha.

Menurut Mayers (2009), pariwisata adalah aktivitas perjalanan yang dilakukan sementara waktu dari tempat tinggal semula ke daerah tujuan dengan alasan bukan untuk menetap atau mencari nafkah melainkan hanya untuk memenuhi rasa ingin tahu, menghabiskan waktu senggang atau berlibur. Sejalan dengan definisi tersebut, Richardson dan Fluker (2009), mendefinisikan pariwisata sebagai kegiatan atau orangorang yang melakukan perjalanan dan tinggal di luar lingkungan mereka selama tidak lebih dari satu tahun berturut-turut untuk bersantai, bisnis, dan tujuan lainnya.

\section{Pengertian Destinasi Pariwisata}

Dalam Undang-undang Nomor 10 tahun 2009 tentang Kepariwisataan disebutkan : Daerah tujuan pariwisata yang selanjutnya disebut Destinasi Pariwisata adalah kawasan geografis yang berada dalam satu atau lebih wilayah administratif yang di dalamnya terdapat daya tarik wisata, fasilitas umum, fasilitas pariwisata, aksesibilitas, serta masyarakat yang saling terkait dan melengkapi terwujudnya kepariwisataan.

Menurut Sunaryo (2013) kerangka pengembangan Destinasi Pariwisata paling tidak harus mencakup komponen-komponen utama sebagai berikut:

a. Objek dan Daya Tarik (Atractions) yang mencakup: daya tarik yang bisa berbasis utama pada kekayaan alam, budaya, maupun buatan/artificial, seperti event atau yang sering disebut sebagai minat khusus (special interent).

b. Aksesibilitas (Accessibility), yang mencakup dukungan sistem transportasi yang meliputi: rute atau jalur transportasi, fasilitas terminal, bandara, pelabuhan dan moda transportasi yang lain.

c. Amenitas (Amenities), yang mencakup fasilitas penunjang dan pendukung wisata yang meliputi: akomodasi, rumah makan (food and baverage), retail, toko cinderamata, fasilitas penukaran uang, biro perjalanan, pusat informasi wisata, dan fasilitas kenyamanan lainnya.

d. Fasilitas pendukung (Ancillary Services) yaitu ketersediaan fasilitas pendukung yang digunakan oleh wisatawan, seperti bank, telekomunikasi, pos, rumah sakit, dan sebagainya.

e. Kelembagaan (Institutions) yaitu terkait dengan keberadaan dan peran masing-masing unsur dalam mendukung terlaksananya kegiatan pariwisata termasuk masyarakat setempat sebagai tuan rumah (host).

Keberhasilan suatu destinasi pariwisata dalam menarik kunjungan wisatawan tentunya tidak lepas dari kecermatan pengelola dalam memahami karakter dan ekspektasi pasar yang selanjutnya dijadikan acuan dalam pengembangan produk dan layanan serta fasilitas pendukung wisata yang terkait di dalamnya.

\section{METODE PENELITIAN}

Jenis data dan sumber data yang digunakan dalam penelitian ini dikelompokkan menjadi dua bagian yaitu : 
1. Data Primer. Dalam penelitian ini, yang termasuk data primer yaitu data yang diperoleh dari kuisioner yang diisi oleh wisatawan yang datang ke Pulau Kelapa atau ke Pulau Harapan di Kepulauan Seribu Jakarta

2. Data Sekunder. Merupakan data yang dikumpulkan, diolah dan diterbitkan oleh Dinas Pariwisata dan Kebudayaan Kepulauan Seribu Jakarta mengenai data jumlah wisatawan ke Kepulauan Seribu Jakarta,

Pada penelitian ini yang menjadi populasi adalah wisatawan ke Pulau Kelapa atau

Pulau Harapan di Kepulauan Seribu Jakarta pada tahun 2016 sebanyak 121.470 wisatawan. Karena keterbatasan tenaga, biaya, dan waktu yang tersedia, maka penelitian dilakukan terhadap sampel dengan penentuan ukuran atau jumlah sampel dengan rumus Slovin yaitu :

$$
n=\frac{N}{1+N(e)^{2}}=\frac{121470}{1+121470(0,1)^{2}}=99,92
$$

Berdasarkan jumlah sampel minimum dengan rumus slovin tersebut di atas maka jumlah sampel yang digunakan dalam penelitian ini sebanyak 100 orang.

Untuk menentukan sampel terpilih akan digunakan teknik purposive sampling yaitu memilih orang yang dianggap mewakili yaitu wisatawan yang telah mengunjungi Pulau Kelapa atau Pulau Harapan di Kepulauan Seribu Jakarta.

Dalam melakukan penelitian operasional variabel dijadikan panduan dalam melakukan tahap penelitian untuk mempermudah dalam mengukur variable dan pembuatan kuesioner. Operasionalisasi variabel dalam penelitian ini disajikan pada Tabel 1 .

Tabel 1. Operasionalisasi Variabel Penelitian

\begin{tabular}{|c|c|c|c|}
\hline Variabel & Konsep Variabel & Dimensi & Indikator \\
\hline \multirow[t]{2}{*}{$\begin{array}{l}\text { Destinasi } \\
\text { Pariwisata }\end{array}$} & \multirow{2}{*}{$\begin{array}{l}\text { Daerah tujuan wisata } \\
\text { yaitu kawasan } \\
\text { geografis yang } \\
\text { berada dalam satu } \\
\text { atau lebih wilayah } \\
\text { administrative }\end{array}$} & $\begin{array}{l}\text { a. Daya Tarik } \\
\text { Wisata }\end{array}$ & $\begin{array}{l}\text { 1. Keindahan pantai } \\
\text { 2. Keindahan terumbu } \\
\text { karang/wisata bawah air } \\
\text { 3. Kebersihan pantai }\end{array}$ \\
\hline & & b. Fasilitas & $\begin{array}{l}\text { 1. Ketersediaan penginapan } \\
\text { 2. Keterjangkauan harga } \\
\text { penginapan } \\
\text { 3. Ketersediaan penjual } \\
\text { makanan dan minuman } \\
\text { 4. Keterjangkauan harga } \\
\text { makanan dan minuman } \\
\text { 5. Ketersediaan fasilitas } \\
\text { permainan air } \\
\text { 6. Keterjangkauan harga } \\
\text { fasilitas permainan air } \\
\text { 7. Ketersediaan air bersih }\end{array}$ \\
\hline
\end{tabular}




\begin{tabular}{|l|l|l|l|}
\hline Variabel & Konsep Variabel & \multicolumn{1}{|c|}{ Dimensi } & \multicolumn{1}{c|}{ Indikator } \\
\hline & & & 1. Kemudahan transportasi \\
& & Aksesibilitas dan & 2. Kenyamanan trasportasi \\
& & & $\begin{array}{l}\text { Transportasi } \\
\text { 3. Keamanan trasportasi } \\
\text { 4. Keterjangkauan biaya } \\
\text { transportasi }\end{array}$ \\
\hline
\end{tabular}

Untuk mengetahui pendapat wisatawan mengenai kualitas destinasi pariwisata Pulau Kelapa atau Pulau Harapan dilakukan dengan analisis deskriptif yaitu dengan mendeskripsikan atau menggambarkan tentang penilaian wisatawan mengenai destinasi pariwisata Pulau Kelapa atau Pulau Harapan dengan 4 pilihan jawaban yang diberi nilai dari 1 sampai 4, yang selanjutnya dihitung nilai rata-rata dari masing-masing indikator atau masing-masing pertanyaan dengan dengan ketentuan seperti pada Tabel 2.

Tabel 2. Nilai, Nilai Rata-rata dan Kriteria Mengenai Kualitas Destinasi Pariwisata

\begin{tabular}{|c|c|l|}
\hline Nilai & Nilai Rata-rata & Kriteria \\
\hline 1 & $1,00-1,55$ & Sangat Tidak Baik \\
\hline 2 & $1,56-2,55$ & Tidak Baik \\
\hline 3 & $2,56-3,55$ & Baik \\
\hline 4 & $3,56-4,00$ & Sangat Baik \\
\hline
\end{tabular}

\section{HASIL DAN PEMBAHASAN}

Dalam mengukur destinasi pariwisata pada penelitian ini digunakan 3 dimensi yaitu : 1. Daya Tarik wisata, 2. Fasilitas wisata, dan 3. Aksesibilitas. Dari 3 dimensi tersebut dibuat 14 pertanyaan (indikator) yang digunakan dengan nilai jawaban terendah sama dengan 1 dan nilai tertinggi adalah 4.

\section{Daya Tarik Wisata Pulau Kelapa dan Pulau Harapan}

Daya tarik wisata yang ada di Pulau Kelapa dan Pulau Harapan yaitu keindahan pantai yang dihiasi dengan pohon mangrove, deretan pulau-pulau kecil yang ada di sekeliling Pulau Kelapa dan Pulau Harapan, deretan perahu nelayan, dan kapal yang ada di dermaga bagian selatan Pulau Kelapa, dan di bagian utara Pulau Harapan, serta Pulau Royal yang sekarang sudah menyatu dengan Pulau Kelapa. Pulau kelapa dan Pulau harapan merupakan pulau yang berpenghuni di kepulauan seribu dan merupakan pulau yang padat penduduk. Pulau Kelapa dan Pulau harapan dikelilingi oleh beberapa pulau kecil seperti Pulau Kotok Kecil, Pulau Kaliange, Pulau Perak, dan Pulau Macan. Wisatawan akan terkagum kagum melihat keindahan alam pantai yang begitu menawan dengan pantai yang biru membuat semua orang ingin langsung berenang. Biasanya wisatawan yang berkunjung ke Pulau Kelapa atau Pulau Harapan selalau berkunjung ke pulau Kotok Kecil karena Pulau Kotok Kecil merupakan lokasi yang sangat tepat untuk snorkeling.

Wisatawan yang datang akan disambut dengan pemandangan pantai yang indah. Wisatawan dapat melihat sunrise (matahari terbit) pada pagi hari dan sunset (matahari terbenam) yang indah pada sore hari di tepian pantai. Wisatawan juga dapat melihat 
burung-burung beterbangan di atas langit sambil duduk di saung-saung kecil yang tersedia di pinggir pantai. Selain itu, dari dermaga wisatawan dapat melihat aktivitas nelayan dan wisatawan yang sedang memancing ikan tak jauh dari bibir pantai. Rekapitulasi kualitas destinasi wisata berdasarkan daya tarik dapat dilihat pada Tabel 3.

Tabel 3. Rekapitulasi Kualitas Daya Tarik Pulau Kelapa dan Pulau Harapan

\begin{tabular}{|l|l|l|l|}
\hline No & Daya Tarik Wisata & Nilai Rata-rata & Kriteria \\
\hline 1 & Keindahan Alam Pantai & 3,61 & Sangat Indah/ Sangat Baik \\
\hline 2 & Keindahan terumbu karang & 3,35 & Indah/Baik \\
\hline 3 & Kebersihan Pantai & 3,09 & Bersih/Baik \\
\hline \multicolumn{2}{|c|}{ Rata-rata } & $\mathbf{3 , 3 5}$ & Baik \\
\hline
\end{tabular}

Sumber : Data Primer yang diolah, 2019

Dari Tabel 3 dapat dilihat bahwa nilai tertinggi yaitu mengenai keindahan alam pantai dengan nilai rata-rata $=3,61$ termasuk katagori sangat indah atau sangat baik, sedangkan nilai terendah yaitu mengenai kebersihan pantai. Rendahnya nilai rata-rata mengenai kebersihan pantai dikarenakan masih ada sampah plastik dan sampah lainnya yang ada di sekitar pantai walaupun setiap hari dibersihkan oleh petugas kebersihan yang digaji oleh pemerintah daerah.

\section{Fasilitas Pariwisata}

Fasilitas Wisata merupakan unsur penting pembentuk produk pariwisata yang berperan menunjang kemudahan dan kenyamanan wisatwan, seperti; ketersediaan sarana akomodasi, prasarana wisata dan sarana wisata pendukung lainnya dalam radius tertentu. Pada penelitian ini fasilitas pariwisata yang dikaji terdiri dari : 1. Ketersediaan Penginapan, 2. Keterjangkauan Harga Penginapan,

3. Ketersediaan Penjual Makanan dan Minuman, 4. Keterjangkauan Harga Makanan dan Minuman, 5. Ketersediaan Fasilitas Permainan Air, 6. Keterjangkauan Harga Fasilitas Permainan Air, dan 7. Ketersediaan Air Bersih di Pulau Kelapa dan Pulau Harapan. Berdasarkan hasil penelitian melalui pendapat atau penilaian responden mengenai Fasilitas wisata di Pulau kelapa dan pulau Harapan disajikan pada Tabel 4.

Tabel 4. Rekapitulasi Kualitas Fasilitas Pariwisata Pulau Kelapa dan Pulau Harapan

\begin{tabular}{|l|l|l|l|}
\hline No & Fasilitas Pariwisata & $\begin{array}{l}\text { Nilai } \\
\text { Rata-rata }\end{array}$ & Kriteria \\
\hline 1 & Ketersediaan Penginapan & 3,42 & Tersedia/Baik \\
\hline
\end{tabular}




\begin{tabular}{|c|c|c|c|}
\hline 2 & Keterjangkauan Harga Penginapan & 3,24 & Terjangkau/Baik \\
\hline 3 & $\begin{array}{llll}\text { Ketersediaan } & \text { Penjual Makanan dan } \\
\text { Minuman } & & & \\
\end{array}$ & 3,39 & Tersedia/Baik \\
\hline 4 & $\begin{array}{l}\text { Keterjangkauan Harga } \text { Makanan dan } \\
\text { Minuman }\end{array}$ & 3,35 & Terjangkau/Baik \\
\hline 5 & Ketersediaan Fasilitas Permainan Air & 2,95 & Tersedia/Baik \\
\hline 6 & $\begin{array}{l}\text { Keterjangkauan Harga Fasilitas Permaian } \\
\text { Air }\end{array}$ & 3,13 & Terjangkau/Baik \\
\hline 7 & Ketersediaan Air Bersih & 2,83 & Tersedia/Baik \\
\hline \multicolumn{2}{|c|}{ Rata-rata } & 3,19 & Tersedia/Baik \\
\hline
\end{tabular}

Sumber : Data Primer yang diolah, 2019

Ketersediaan penginapan berdasarkan penilaian wisatawan nilai rata-rata 3,42 masuk kategori baik. Penginapan yang ada di Pulau Kelapa dan Pulau Harapan adalah rumah tinggal penduduk (homestay). Keberadaan homestay membuat wisatawan berada pada lingkungan rumah yang ramah dan merasa dekat dengan penduduk lokal di Pulau Kelapa dan Pulau Harapan. Wisatawan juga mengganggap penginapan tersebut layak karena penginapan disana berupa rumah yang dirawat oleh warga setempat, yang pada umumnya dilengkapi dengan fasilitas AC namun ada juga yang hanya ditengkapi dengan kipas angin.

Berwisata ke Pulau Kelapa atau ke Pulau Harapan harus menginap karena lamanya perjalanan dari daratan Jakarta menuju Pulau Kelapa atau Pulau Harapan yaitu antara 3 sampai 5 jam. Homesty ini banyak tersedia terutama di pulau harapan. Harga yang per kamar dengan fasilitas AC dan kamar mandi di dalam bisa ditempati 2 sampai 3 orang Rp sekitar Rp 200000 sampai Rp 300.000. Rumah dengan 2 kamar ada ruang tamu dilengkapi AC harga sekitar Rp 700.000 sampai Rp 800.000. Sedangkan Rumah dengan 3 kamar tidur ada ruang tamu dilengkapi AC harga sekitar Rp 1.000.000 sampai $\mathrm{Rp}$ 1.200.000. Pendapat responden mengenai keterjangkauan harga penginapan di Pulau Kelapa dan Pulau Harapan yaitu sebesar 3,24 yaitu termasuk kategori terjangkau harga penginapan di Pulau Kelapa dan Pulau Harapan. Setelah sampai di daerah tujuan wisata biasanya wisatawan memerlukan makanan dan minuman sebagai kebutuhan utama, bagi wisatawan yang tidak membawa perbekalan makanan dan minuman mereka akan membelinya di daerah tujuan wisata. Pendapat responden mengenai keterjangkauan harga makanan dan minuman di Pulau Kelapa dan Pulau Harapan berpendapat tersedia penjual makanan dan minuman dengan nilai rata-rata yaitu sebesar 3,39 yaitu termasuk kategori tersedianya penjual makanan dan minuman.

Pendapat responden mengenai keterjangkauan harga makanan dan minuman di Pulau Kelapa dan Pulau Harapan yaitu paling banyak berpendapat harga makanan dan minuman di Pulau Kelapa nilai rata-rata yaitu sebesar 3,35 yaitu termasuk kategori terjangkau. Pendapat responden mengenai ketersedian fasilitas permainan air di Pulau Kelapa dan Pulau Harapan Berdasarkan nilai rata-rata yaitu sebesar 2,95 yaitu termasuk kategori tersedia fasilitas permainan air di Pulau Kelapa dan Pulau Harapan. Permainan air yang ada di pulau harapan berupa Donut, Banana Boat, dan snorkling.

Harga paket permainan donut dan banana boat Rp 35.000 per orang untuk lama waktu sekitar 15 menit, namun harga tersebut masih bisa ditawar kalau jumlah pengunjung atau wisatawan sedikit menjadi Rp 20.000 per orang. Pendapat responden mengenai keterjangkauan harga fasilitas permainan air di Pulau Kelapa dan Pulau Harapan dilihat dari nilai rata-rata yaitu sebesar 3,13 yaitu termasuk kategori terjangkau 
harga fasilitas permainan air di Pulau Kelapa dan Pulau Harapan. Ketersediaan air bersih sangat penting di destinasi wisata, apalagi di destinasi wisata pantai, karena setelah melalukan permainan air wisatawan perlu bilas atau mandi dengan menggunakan air tawar yang bersih. Berdasarkan pendapat responden, nilai rata-rata yaitu sebesar 2,83 yaitu termasuk kategori tersedia air bersih di Pulau Kelapa dan Pulau Harapan.

\section{Aksesibilitas}

Akses menuju Pulau Kelapa atau Pulau Harapan karena merupakan pulau yang berpenghuni dan dengan jumlah penduduk banyak maka sangat mudah dijangkau melalui transportasi laut yang sudah memadai, baik yang miliki masyarakat maupun pemerintah. Terdapat beberapa akses untuk menuju ke Pulau Kelapa dan Pulau Harapan, yaitu:

\section{a. Dari Dermaga Marina Ancol}

Wisatawan yang akan berkunjung ke Pulau Kelapa atau Pulau Harapan bisa berangkat dari Dermaga Marina Ancol dengan menggunakan kapal cepat (speed boat) dengan lama perjalanan sekitar 90 menit ( 1,5 jam). Kapal akan berangkat jam 8.00 pagi, penumpang harus sudah berada di kapal paling lambat jam 7.30. Ongkos naik kapal cepat ini untuk menuju Pulau Kelapa atau Pulau Harapan sebesar Rp 190. 000,- per orang untuk sekali keberangkatan untuk hari Senin sampai hari Jumat, sedangkan untuk hari Sabtu, Minggu, dan hari libur Rp 235.00,- per orang.

\section{b. Dari Kali Adem}

Wisatawan yang akan berkunjung ke Pulau Kelapa atau Pulau Harapan bisa berangkat dari Dermaga Kali Adem dengan menggunakan kapal milik masyarakat dan milik Dinas Perhubungan, lama perjalanan 3 sampai 4 jam. Kapal akan berang-kat jam 8.00 pagi, penumpang harus sudah berada di kapal paling lambat jam 7.30. Harga Tiket Rp. 55.000, Retribusi peron Rp.2.000.

\section{c. Dari Pelabuhan Sunda Kelapa}

Wisatawan yang akan berkunjung ke Pulau Kelapa atau Pulau Harapan bisa berangkat dari Dermaga Sunda Kelapa dengan menggunakan kapal Sabuk Nusantara 66 dengan lama perjalanan sekitar 5 jam. Kapal akan berangkat jam 8.00 pagi, penumpang harus sudah berada di kapal paling lambat jam 7.30. Ongkos naik kapal menuju Pulau Kelapa atau Pulau Harapan sebesar Rp 15.000,- (lima belas ribu rupiah) per orang.

Hasil penelitian pendapat wisatawan mengenai aksesibilitas Pulau Kelapa dan Pulau Harapan disajikan pada Tabel 5.

Tabel 5. Rekapitulasi Kualitas Aksesibilitas Pulau Kelapa dan Pulau Harapan

\begin{tabular}{|l|l|l|l|}
\hline No & Aksesibilitas & $\begin{array}{l}\text { Nilai Rata- } \\
\text { rata }\end{array}$ & Kriteria \\
\hline 1 & Kemudahan Transportasi & 2,88 & Mudah/Baik \\
\hline 2 & Kenyamanan Transportasi & 3,26 & Nyaman/Baik \\
\hline 3 & Keamanan Transportasi & 3,13 & Aman/Baik \\
\hline
\end{tabular}




\begin{tabular}{|l|l|l|l|}
\hline 4 & Keterjangkauan Biaya Transportasi & 3,39 & Terjangkau/Baik \\
\hline Rata-rata & $\mathbf{3 , 1 7}$ & Baik \\
\hline
\end{tabular}

Sumber : Data Primer yang diolah, 2019

Dari Tabel 5 dapat dilihat bahwa nilai rata-rata untuk kualitasaksesibilitas menuju Pulau Kelapa dan Pulau Harapan diperoleh rata-rata 3,17 termasuk katagori baik. Nilai rata-rata tertinggi yaitu mengenai keterjangkauan biaya transortasi, yaitu kalau menggunakan Kapal Sabuk Nusantara 66 sebesar Rp 15.000 per orang. Nilai rata-rata terendah yaitu mengenai kemudahan transportasi, yaitu kurang tersedianya rambu-rambu atau petunjuk arah menuju Dermaga tempat bersandarnya kapal baik di Kali Adem maupun di Sunda Kelapa, selain itu jumlah kapal dan waktu berangkat kapal masih terbatas. Berdasarkan Tabel 3, 4 dan 5 dapat disajikan rekapitulasi kualitas destinasi wisata Pulau Kelapa dan Pulau Harapan di Kepulauan Seribu disajikan pada Tabel 6.

Tabel 6. Rekapitulasi Kualitas Destinasi Wisata Pulau Kelapa dan Pulau Harapan

\begin{tabular}{|l|l|l|l|}
\hline No & Destinasi Wisata & $\begin{array}{l}\text { Nilai Rata- } \\
\text { rata }\end{array}$ & Kriteria \\
\hline \multicolumn{2}{|l|}{ Daya Tarik Wisata } & $\mathbf{3 , 3 5}$ & Baik \\
\hline 1 & Keindahan Alam Pantai & 3,61 & $\begin{array}{l}\text { Sangat Indah/ } \\
\text { Sangat Baik }\end{array}$ \\
\hline 2 & Keindahan terumbu karang & 3,35 & Indah/Baik \\
\hline 3 & Kebersihan Pantai & 3,09 & Bersih/Baik \\
\hline Fasilitas Pariwisata & $\mathbf{3 , 1 9}$ & Tersedia/Baik \\
\hline 4 & Ketersediaan Penginapan & 3,42 & Tersedia/Baik \\
\hline 5 & Keterjangkauan Harga Penginapan & 3,24 & Terjangkau/Baik \\
\hline 6 & Ketersediaan Penjual Makanan dan Minuman & 3,39 & Tersedia/Baik \\
\hline 7 & Keterjangkauan Harga Makanan dan Minuman & 3,35 & Terjangkau/Baik \\
\hline 8 & Ketersediaan Fasilitas Permainan Air & 2,95 & Tersedia/Baik \\
\hline 9 & Keterjangkauan Harga Fasilitas Permaian Air & 3,13 & Terjangkau/Baik \\
\hline 10 & Ketersediaan Air Bersih & 2,83 & Tersedia/Baik \\
\hline Aksesibilitas & $\mathbf{3 , 1 7}$ & Baik \\
\hline 11 & Kemudahan Transportasi & 2,88 & Mudah/Baik \\
\hline 12 & Kenyamanan Transportasi & 3,26 & Nyaman/Baik \\
\hline 13 & Keamanan Transportasi & 3,13 & Aman/Baik \\
\hline 14 & Keterjangkauan Biaya Transportasi & 3,39 & Terjangkau/Baik \\
\hline \multicolumn{2}{|l|}{ Rata-rata } & $\mathbf{3 , 2 4}$ & Baik \\
\hline
\end{tabular}

Sumber : Data Primer yang diolah, 2019

Berdasarkan Tabel 6 dapat dilihat bahwa nilai rata-rata mengenai kualitas destinasi wisata yaitu 3,24. Rata-rata tertinggi yaitu dimensi daya Tarik wisata dengan nilai rata-rata $=$ 3,35 , sedangkan nilai rata-rata terendah yaitu dimensi aksesibilitas dengan nilai rata-rata $=3.17$.

\section{KESIMPULAN DAN SARAN} berikut

Berdasarkan hasil penelitian ini maka dapat dibuat kesimpulan dan Saran sebagai 


\section{Kesimpulan}

1. Penilaian wisatawan mengenai indikator kualitas destinasi pariwisata Pulau Kelapa dan Pulau Harapan di Kepulauan Seribu Jakarta dengan skala penilaian 1 sampai 4, diperoleh rata-rata $=3.24$ (kategori baik).

2. Indikator kualitas destinasi wisata yang lebih tinggi dari rata-rata $(3,24)$ yaitu : 1) Keindahan alam pantai, 2) Keindahan terumbu karang, 3) Ketersediaan penginapan, 4) Ketersediaan penjual makanan dan minuman, 5) Keterjangkauan harga makanan dan minuman, 6) Kenyamanan transportasi, 7) Keterjangkauan biaya transportasi.

3. Indikator kualitas destinasi wisata yang lebih rendah dari rata-rata $(3,24)$ yaitu : 1) Kebersihan pantai, 2) Ketersediaan fasilitas permainan air, 3) Keterjangkauan harga fasilitas permainan air, 4) Ketersediaan air bersih, 5) Kemudahan transportasi, 6) Keamanan transportasi.

\section{Saran}

1. Pihak pemerintah, masyarakat, dan pengelola kawasan wisata Pulau Kelapa dan Pulau Harapan harus secara bersama-sama berusaha untuk mempertahankan, meningkatkan kualitas destinasi wisata yang ada, dan terus mempromosikan destinasi wisata terutama pulau kelapa, agar jumlah wisatawan yang datang terus meningkat.

2. Kebersihan pantai dan lingkungan sekitar Pulau Kelapa dan Pulau Harapan harus benar-benar dijaga dengan menyediakan tempat tempat sampah disepanjang jalan dan agar wisatawan merasa nyaman, karena pemandangan yang indah akan terganggu jika lingkungannya kotor dan banyak sampah. Masyarakat sekitar perlu diberi pengarahan sadar wisata agar benar-benar menjaga kebersihan pantai dan lingkungan sekitar rumahnya. Pasukan Orange yang bertugas membersihkan lingkungan perlu diberi arahan agar Kawasan pantai dan lingkungan sekitarnya senantiasa terjaga kebersihannya.

3. Untuk penyewaan perahu atau fasilitas permainan air sebaiknya bisa dilakukan secara membayar perorangan agar harga terjangkau untuk wisatawan yang datang secara perorangan atau datang bersama teman dengan jumlah kurang dari 10 orang atau berwisata tidak harus melalui travel.

4. Mengingat ketersediaan air bersih atau toilet umum di Pulau Harapan masih sedikit apalagi di Pulau Kelapa , sebaiknya pemerintah setempat menyediakannya untuk kenyamana para wisatawan.

5. Kemudahan transportasi harus ditingkatkan, seperti dibuat rambu-rambu petunjuk untuk menuju dermaga Kali Adem dan Dermaga Sunda Kelapa di pintu gerbang utama, untuk menghindari kesalahan jalan menuju dermaga tersebut.

6. Kenyamanan wisatawan selama di kapal harus ditingkatkan, yaitu sebaiknya kapal tidak diisi penumpang melebihi kapasitas maksimum sehingga wisatawan tidak kebagian tempat duduk atau duduk berdesak-desakan.

7. Untuk menjaga keamanan selama dalam perjalanan di laut sebaiknya tersedia Jaket pengaman dalam jumlah yang sesuai dengan jumlah penumpang dan dibagikan ke penumpang untuk menjaga hal-hal yang tidak diharapkan.

\section{DAFTAR PUSTAKA}


Basiya, R., \& Rozak, H. A. (2012). Kualitas Dayatarik Wisata, Kepuasan Dan Niat Kunjungan Kembali Wisatawan Mancanegara Di Jawa Tengah. Jurnal Ilmiah Dinamika Kepariwisataan, 11(2).

Damardjati, R. S. (1992). Istilah-Istilah Dunia Pariwisata. pradnya paramita..

Kirom, N. R., Sudarmiatin, S., \& Putra, I. W. J. A. (2016). Faktor-Faktor Penentu Daya Tarik Wisata Budaya dan Pengaruhnya Terhadap Kepuasan Wisatawan. Jurnal Pendidikan: Teori, Penelitian, dan Pengembangan, 1(3), 536-546.

Marpaung, H., \& Bahar, H. (2002). Pengantar pariwisata. Bandung: Alfabeta.

Mayers, G. E \& Mayers, M.T. (2009). The Dynamics OF Human Communication. Sixth Edition. Mc Graw Hill, Inc: New York.

Mill, R. C, Alih Bahasa Sastro Tribudi. (2011). Tourism The international Business, Edisi Bahasa Indonesia. Penerbit PT Raja Grafindo Persada. Jakarta.

Mulyadi. (2010). Daya Tarik Wisata. Edisi Keenam. Buku 1. Jakarta: Salemba Empat. Jakarta.

Pendit Nyoman, S. (2010). Pengantar Ilmu Pariwisata..

Razak, A., \& Suprihardjo, R. (2013). Pengembangan Kawasan Pariwisata Terpadu di Kepulauan Seribu. Jurnal Teknik ITS, 2(1), C14-C19.

Richardson, J. I., \& Fluker, M. (2004). Understanding and managing tourism. Pearson Education Australia.

Sunaryo, B. (2013). Kebijakan pembangunan destinasi pariwisata: konsep dan aplikasinya di Indonesia (No. 1). Penerbit Gava Media Kebijakan Pembangunan Destinasi Pariwisata: Konsep dan Aplikasinya di Indonesia.. 